\title{
Surgery of Superior Cerebellar Artery Aneurysm (SCA)
}

\author{
Miguel A. Arraez, Miguel Dominguez, \\ Cristina Sanchez-Viguera, Bienvenido Ros, \\ and Guillermo Ibañez
}

\subsection{Signs and Symptoms}

Patient a 57 years old male, a persistent headache was evaluated by neurologists. MRI was done, and incidental superior cerebellar artery (SCA) aneurysm was discovered after assessment of abnormal image at the lateral aspect of the mesencephalon. CT-angio and angiography (Fig. 18.1) showed an aneurysm with saccular form at proximal portion of right SCA. Endovascular treatment was precluded by neuroradiologist due to the morphological characteristics of the aneurysm's neck [1-3].

\subsection{Investigation}

The most striking neuroradiological examination was angiography and CT-angio. The superior cerebellar and posterior cerebral arteries were seen arising from a common origin ("N" type according to the McCullough classification of the anatomical variations of the circle of Willis) [4]. The aneurysm was close to the origin of the artery from basilar trunk at the anterior pontomesencephalic segment. The relation neck/dome suggested a good indication for surgery.

\footnotetext{
M. A. Arraez $(\bowtie) \cdot$ M. Dominguez $\cdot$ C. Sanchez-

Viguera $\cdot$ B. Ros $\cdot$ G. Ibañez

Department of Neurosurgery, Carlos Haya University

Hospital, Malaga, Spain

e-mail: marraezs@uma.es
}

One of the important points before surgery is the appropriate anatomical characterization of the origin and location and morphology of the aneurysm. Among the segments of the SCA (prepontine, ambient, and quadrigeminal), the aneurysm was seen at the prepontine portion of the artery. It is noteworthy that in this segment, the SCA is giving off perforating branches to the pons before the origin of the lateral (marginal) branch. It is also interesting to mention that SCA aneurysms usually arise at the $2 \mathrm{~mm}$ proximal to the artery of origin (usually the basilar trunk). SCA aneurysms are not frequent $(1.7 \%$ of the total), but $42 \%$ of the cases are found in the context of multiple aneurysms. Unlike our patient, the most common presentation is $\mathrm{SAH}(60 \%)$ followed by compression of III, IV, or V cranial nerve. The hemorrhagic presentation is frequently seen in lesions smaller than $7 \mathrm{~mm}$.

\subsection{Preoperative Preparation}

Preoperative preparation is crucial in aneurysm surgery. Relaxation of the brain is of outstanding importance. The timing for surgery is decided in accordance to the clinical presentation (SAH, incidental aneurysm), morphology and size of the aneurysm, Hunt and Hunt scale, and choice of the surgical approach. Not infrequently posterior fossa lesions require significant brain retraction making advisable delayed procedure. In our 

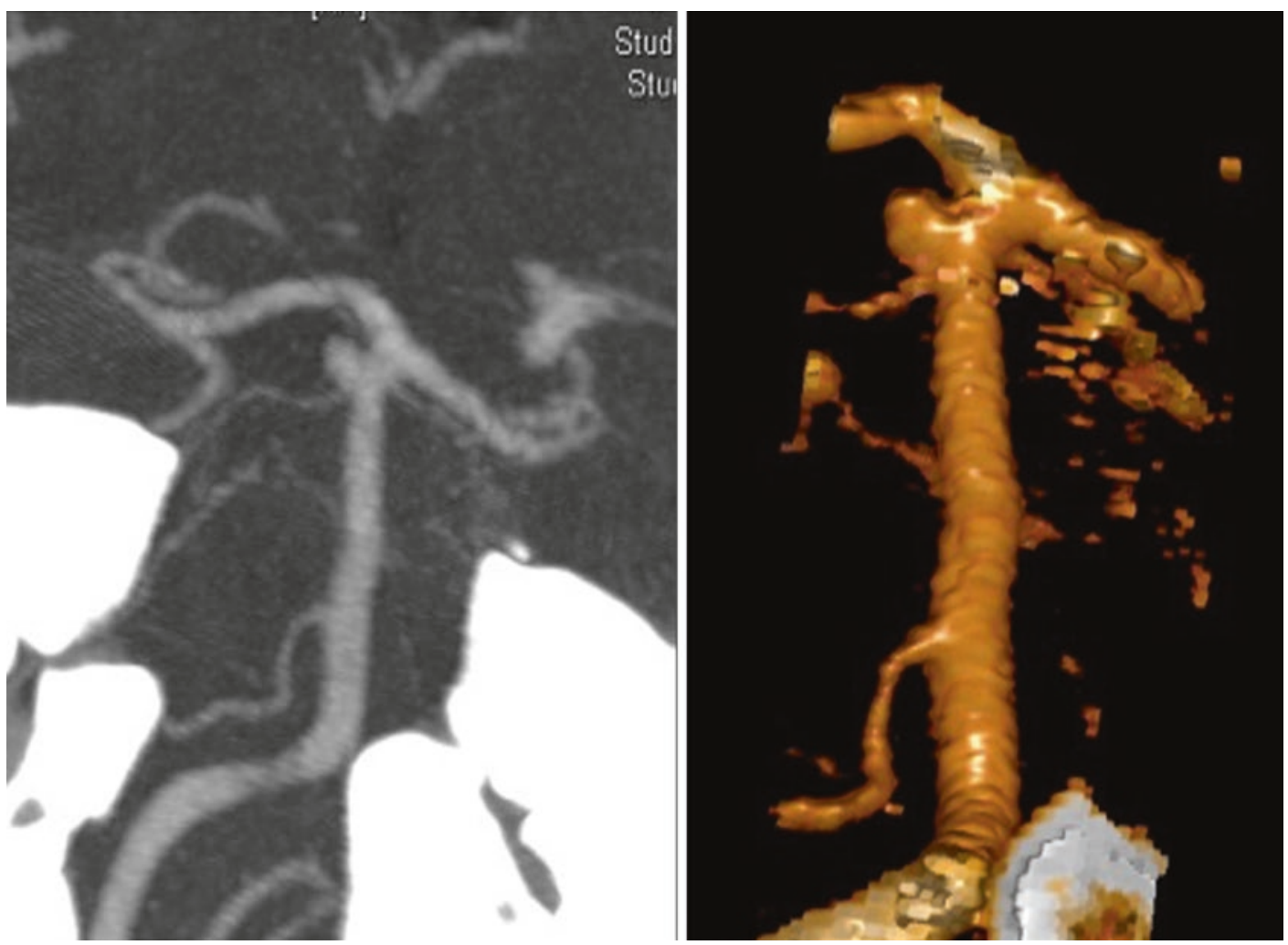

Fig. 18.1 Aneurysm of the right superior cerebellar artery in a 57-year-old male. Incidental finding. Angiography and CT-angio

patient (incidental aneurysm) elective surgery was done with preoperative spinal drainage and osmotic diuretics as perioperative adjunct measures.

\subsection{Steps of Surgery}

The approach selected for this case was a right frontotemporal craniotomy with limited zygomatic osteotomy (no need for orbito-zygomatic osteotomy in our opinion). The choice of approach for exposure of SCA aneurysm will depend on the segment where the lesion lies. The SCA might be separated into four segments: the pontine segment also called as anterior pontomesencephalic segment, the ambiens segment also called as the lateral pontomesencephalic segment, the quadrigeminal segment also called as the cerebellomesencephalic segment, and then the last one which is called cortical segment. According to location of aneurysm in one of these segments, the following approaches can be used: subtemporal, pretemporal extradural with clinoidectomy, subtemporal with addition of zygomatic or orbito-zygomatic osteotomy, and presigmoid and posterior fossa suboccipital. The latter is used to approach the cortical segment and the former to get access to the tentorial incisura and perimesencephalic segments of the SCA $[5,6]$.

In our patient, the lesion was placed at the pontine segment. This part of SCA is located between dorsum sellae and the upper brainstem [5]. This segment starts at the exit of the SCA from the basilar artery. The aneurysm in the presented case arose in this point (as very frequently seen in SCA aneurysms). In this area, special care must be taken as basilar artery and SCA at its origin show intermingled perforating vessels. Another relevant anatomical structure is the III nerve, constantly 


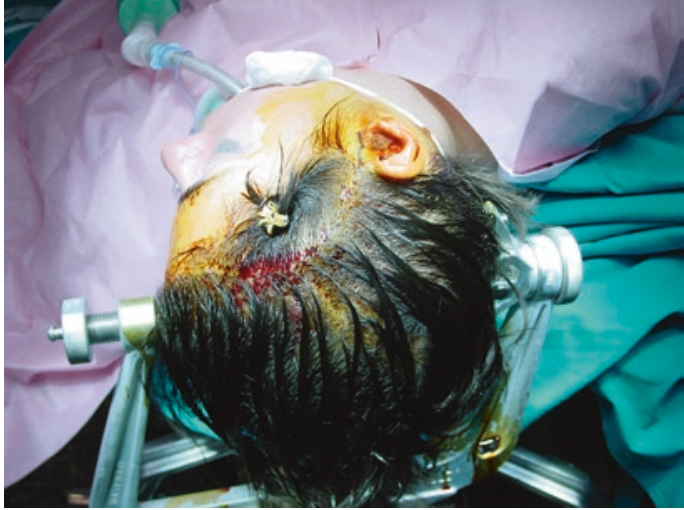

Fig. 18.2 Positioning of the head for the surgical approach to the right tentorial incisura. Left rotation and extension of the head. No hair shaving

above SCA and below the PCA (posterior cerebral artery). Due to location of aneurysm at the anterior pontomesencephalic segment, the choice of the approach was a subtemporal-pretemporal transzygomatic approach.

The patient was placed in supine position, with left rotation and slight extension of the head (Fig. 18.2). We usually do not shave the hair (previously prepared with antiseptic solution). A skin incision is made curvilinear from the hairline to anterior of tragus. After skin incision, the identification of the fascia at temporal is very important; there are superficial and deep layer of the fascia and dissection of the fat in between to avoid injury to facial nerve that innervates the frontal side. The zygomatic bone needs to be exposed. In our opinion, only a limited osteotomy is necessary to increase the reflection of the temporal muscle after detachment from the temporal bone (Figs. 18.3 and 18.4) instead of the more time-consuming orbito-zygomatic osteotomy that adds unnecessary morbidity. This maneuver diminishes the retraction of the temporal lobe increasing also the view of the tentorial incisura region. A frontotemporal craniotomy is done and dura is opened (Fig. 18.5). The brain is relaxed after mannitol and CSF release through spinal drainage or through opening the arachnoid layer at the basal cisterns in the context of the microsurgical approach. The intradural part of

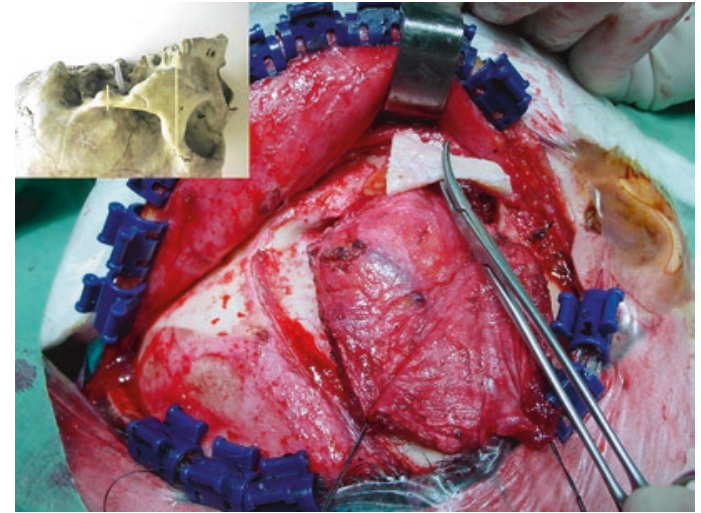

Fig. 18.3 Exposure of the zygomatic bone after careful dissection of the layers of the deep temporal fascia. A very limited zygomatic osteotomy is done instead of orbitozygomatic osteotomy (see the osteotomy lines depicted in upper left corner)

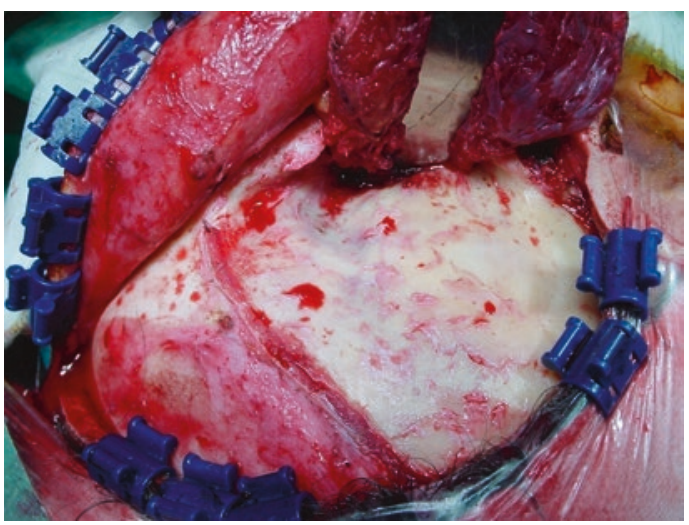

Fig. 18.4 Reflection downward of the temporal muscle exposes adequately the temporal bone to increase the temporal component of the craniotomy

the operation starts with a very minimal retraction just to hold the temporal lobe. The tentorial incisura is exposed with the relevant structures. The exposure will allow the recognition of the anterolateral mesencephalon, carotid artery, posterior communicating artery and its perforating arteries, PCA, SCA, and oculomotor nerve, typically running below PCA and above SCA (Fig. 18.6). Also, IV nerve can be seen in its typical course along tentorium [7].

All these steps were done in our patient. The III nerve was right in the direction of our sight, 


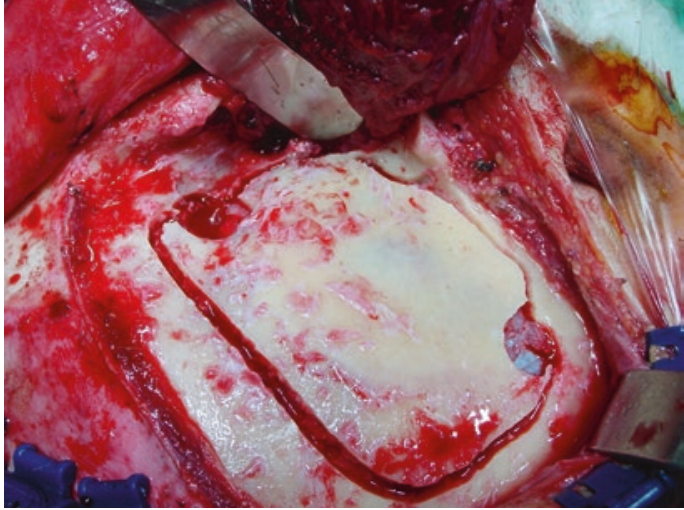

Fig. 18.5 Right frontotemporal craniotomy. The frontal component is small. The temporal flap almost reaches the level of the middle fossa floor to diminish the intradural retraction of the temporal lobe

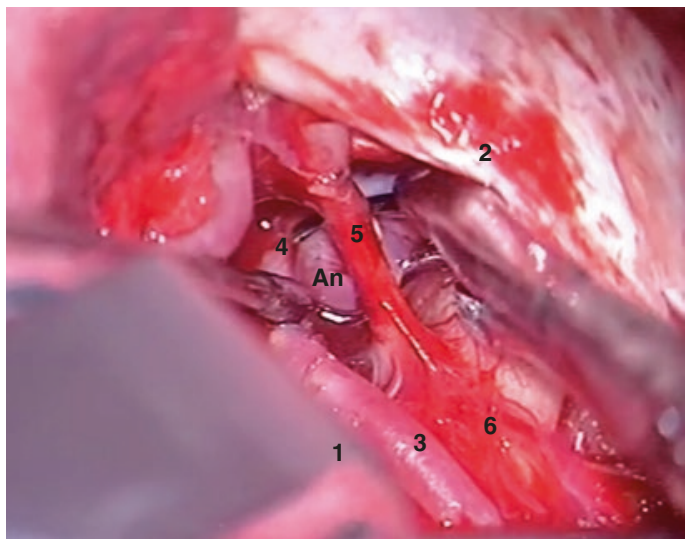

Fig. 18.6 Exposure of the right tentorial incisura and pontomesencephalic segment of the SCA. Temporal lobe retracted (1), tentorium (2), posterior cerebral artery (3), basilar artery (4), III nerve interposed in the direction of the sight of the surgeon (5), right mesencephalon (6), and aneurysm dome right before clipping

making slightly difficult in the identification and clipping of the neck. A Sugita clip was use to exclude the aneurysm from the circulation (Fig. 18.7). The effectiveness of the procedure was confirmed by means of ICG intraoperative angiography (Fig. 18.8).

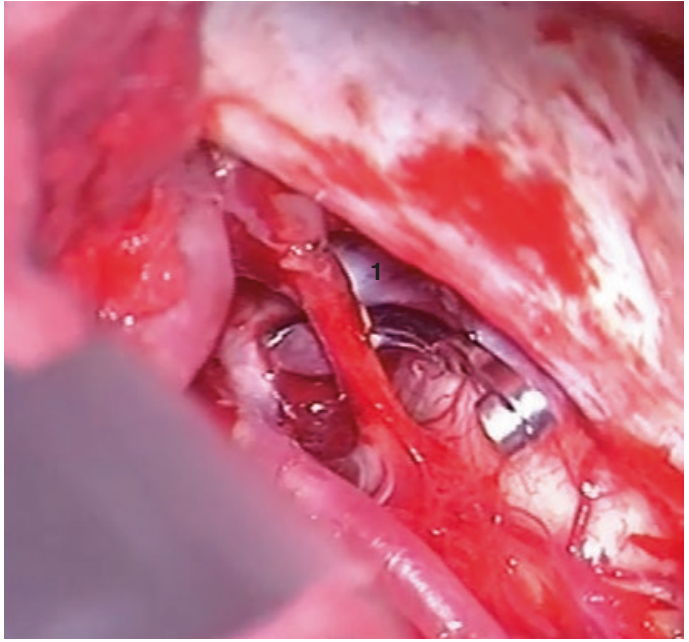

Fig. 18.7 SCA aneurysm clipped. The SCA main trunk has been preserved (1)

\subsection{Expert Opinion/Suggestion to Avoid Complication}

One of the possible complications would come from bad exposure due to wrong choice of the surgical approach $[8,9]$. Wrong approaches very seldom happen, at the anterior circle of Willis, but the posterior circle offers many more possibilities and difficulty to reach appropriately the aneurysm neck. The anatomy of the vessels and their variations along with morphology of the aneurysm, its neck, and relation with perforating vessels are of course of paramount importance. Thus, preoperative assessment (angiography, CT-angio) is absolutely crucial to establish the choice of the approach $[10,11]$. The segment in which the aneurysm is located and the relation of the aneurysm and posterior clinoid must be carefully evaluated. The segment harboring the lesion will suggest anterior, lateral, or posterior approach. In regard to the relation of the aneurysm and posterior clinoid, a very low origin would preclude the use of anterior intradural approaches. 

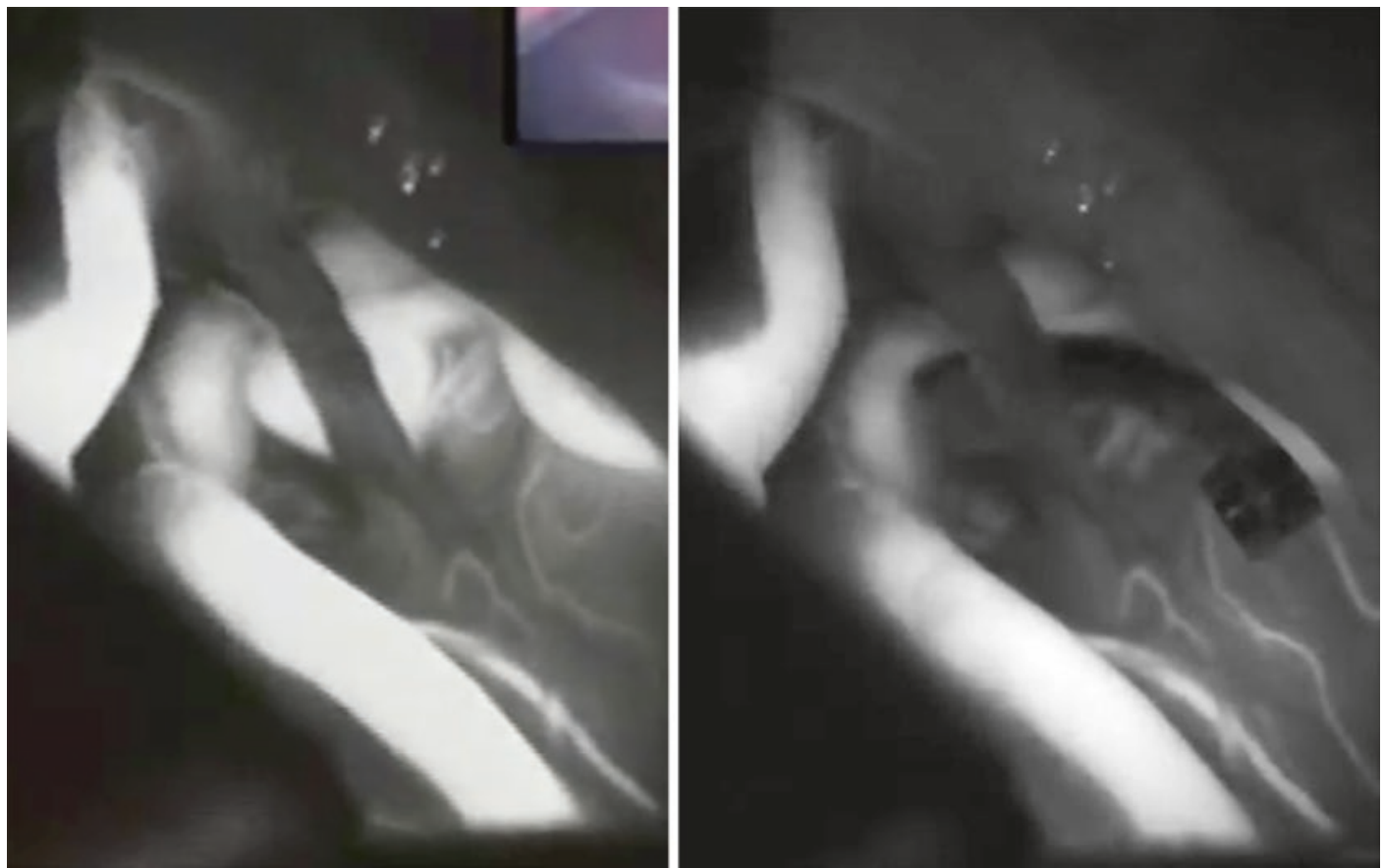

Fig. 18.8 ICG intraoperative angiography before (a) and after clipping (b) showing exclusion of the aneurysm. Basilar artery (1), posterior cerebral artery (2), superior cerebral artery (3), SCA aneurysm (4), and III nerve interposed (5)

Another frequent source of complications in para-temporal approaches is the improper management of the temporal lobe (contusion, infarction, hemorrhage). In our selected approach (anterolateral), a very gentle retraction of the temporal lobe must be done lifting the tip not subtemporally but anteriorly. No veins are encountered in a long avenue from the sylvian fissure (anterior and medial) to the Labbé area (posterior and lateral). This lifting of the temporal lobe is very well tolerated unlike some other forms of compression or distortion. Sylvian fissure usually doesn't need to be opened. Care must be taken not to tear sylvian veins during the exposure. The proper extension of the head and gravity can help diminish any harmful effect of the retractors over the temporal lobe.

\subsection{Postoperative Measures}

This approach doesn't differ from other approaches in regard to the general care after other aneurysm surgery procedures or craniotomy. We administer postoperative calcium antagonist, antiepileptic drugs, and low weight subcutaneous heparin along with early mobilization. The external lumbar drainage is removed $24 \mathrm{~h}$ after surgery.

\section{References}

1. Chaloupka JC, Putman CM, Award IA. Endovascular therapeutic approach to peripheral aneurysms of the superior cerebellar artery. AJNR Am J Neuroradiol. 1996; 17:1338-42. 
2. Jin SC, Park ES, Kwon do H, Ahn JS, Kwun BD, Kim $\mathrm{CJ}$, et al. Endovascular and microsurgical treatment of superior cerebellar artery aneurysms. J Cerebrovasc Endovasc Neurosurg. 2012;14:29-36.

3. Peluso JP, van Rooij WJ, Sluzewski M, Beute GN. Superior cerebellar artery aneurysms: incidence, clinical presentation and midterm outcome of endovascular treatment. Neuroradiology. 2007;49:747-51.

4. McCullough AN. (Rewritten posthumously for the author by Howard K. Suzuki). Some anomalies of the arterial circle (of Willis) and related vessels. Anat Rec. 1952;142:537-43.

5. Bozboga M, Canbolat A, Savas A, Türker K. Aneurysms arising from the medial branch of the superior cerebellar artery. Acta Neurochir. 1996;138:1013-4.

6. Hardy DG, Peace DA, Rhoton AL Jr. Microsurgical anatomy of the superior cerebellar artery. Neurosurgery. 1980;6:10-28.
7. Collins TE, Mehalic TF, White TK, Pezzuti RT. Trochlear nerve palsy as the sole initial sign of an aneurysm of the superior cerebellar artery. Neurosurgery. 1992;30:258-61.

8. Gács G, Viñuela F, Fox AJ, Drake CG. Peripheral aneurysms of the cerebellar arteries. Review of 16 cases. J Neurosurg. 1983;58:63-8.

9. Yasargil MG. Microsurgical anatomy of the basal cisterns and vessels of the brain, diagnostic studies, general operative techniques and pathological considerations of the intracranial aneurysms. Stuttgart, Germany: Georg Thieme Verlag; 1984.

10. Day JD, Fukushima T, Giannotta SL. Cranial base approaches to posterior circulation aneurysms. J Neurosurg. 1997;87:544-54.

11. Nair P, Panikar D, Nair AP, Sundar S, Ayiramuthu P, Thomas A. Microsurgical management of aneurysms of the superior cerebellar artery-lessons learnt: an experience of 14 consecutive cases and review of the literatura. Asian J Neurosurg. 2015;10:47.

Open Access This chapter is licensed under the terms of the Creative Commons Attribution 4.0 International License (http://creativecommons.org/licenses/by/4.0/), which permits use, sharing, adaptation, distribution and reproduction in any medium or format, as long as you give appropriate credit to the original author(s) and the source, provide a link to the Creative Commons license and indicate if changes were made.

The images or other third party material in this chapter are included in the chapter's Creative Commons license, unless indicated otherwise in a credit line to the material. If material is not included in the chapter's Creative Commons license and your intended use is not permitted by statutory regulation or exceeds the permitted use, you will need to obtain permission directly from the copyright holder. 